\title{
Scale effects on the hydrological impact of upland afforestation and drainage using indices of flow variability: the River Irthing, England
}

\author{
D. Archer \\ J B AConsulting Engineers and Scientists, South Barn, Broughton Hall, Skipton, BD23 3AE, UK \\ Email: davearcher@yahoo.com
}

\begin{abstract}
Frequent assertions by river users that rivers in northern England now rise and fall more quickly than in the past, have never been validated by analysis on catchments of more than $10 \mathrm{~km}^{2}$. The method using indices of flow variability provides a basis for making direct measurements of the annual number and duration of pulses, i.e. rises above a given flow, and for comparing catchments of different sizes. A comparison is made between the small afforested headwater Coalburn catchment $\left(1.5 \mathrm{~km}^{2}\right)$ and the larger River Irthing catchment $\left(335 \mathrm{~km}^{2}\right)$ on which the afforested area comprises $19 \%$. A simple but effective means is provided for decoupling the effect of climatic variability from the effects of land use. The analysis shows that major changes have occurred on the small catchment, first with rising pulse numbers after pre-afforestation drainage, then with a much greater progressive decrease in pulse number accompanied with increasing pulse duration. In contrast, the larger catchment shows little change in variability indices from the beginning of its record in 1968 until the late 1980s after which the pattern of change mirrors that at Coalburn but the proportional change is much smaller. The direction of change is the opposite of that asserted by river users.
\end{abstract}

Keywords: hydrology, flow variability, land-use impacts, forests, scale effects

\section{Introduction}

The problem of scale is a fundamental one in hydrology (Dooge, 1989). The US National Research Council (NRC, 1991) identified the 'scale problem' as a major unsolved problem in hydrology. Newson (1994) describes scale effects as one of hydrology's greatest experimental problems in that "cause and effect claims are best elucidated by research in small catchments whilst impacts are of much greater relevance in much larger basins". The relative importance of different processes changes from the field plot to catchment and with increasing size of catchment. At the plot scale, processes of interception, infiltration and storage dominate but, with increasing catchment size, channel processes assume a greater role in the stream hydrograph. Thus, there are considerable problems in extrapolating results from one scale to another.

Nowhere are scale issues more evident than in the impact of land use change. For example, Robinson (1990) has shown that the impact of drainage on rainfall runoff response may operate in different directions at the field scale and the small catchment scale depending on the soil type, the relative importance of channel 'improvement' and the location of land use changes in relation to the catchment outflow.

Apart from the change in dominant processes, three other factors make it difficult to identify clear hydrological signals resulting from land use change at the catchment scale.

(1) Land use changes occur as a patchwork over a catchment. A reduced rainfall runoff response time in lower or mid-catchment may have a counteracting effect on a reduced response time in the upper catchment. Land use changes can be studied under controlled conditions at the plot scale; the spatial distribution of changes over the catchment may be fairly random and dependent on such fickle factors as changing government policy and the interest of individual landowners. 
(2) Whilst land use changes at the plot scale or small catchment may have a closely defined interval of occurrence (e.g. crop planting, drainage for afforestation) such changes at the catchment scale may be spread over a period of years or decades with land use effects on runoff operating in different directions depending on the stage within a cycle of development (e.g. drainage, afforestation, progressive tree maturity, felling, etc.).

(3) There is inherent variability in runoff at time scales which differ from storm event to seasonal, annual and longer term weather and climate change. It may be more difficult to distinguish the comparative influences of land use from climate variability on the large catchment than on the field plot or small catchment.

As a result of these complicating factors, there has been no unequivocal demonstration of the hydrological effects of upland drainage and afforestation on catchments greater than $10 \mathrm{~km}^{2}$ in the UK (O'Connell, 2003). Attempts at parameterisation of land use effects in catchment modelling without calibration have been said to demonstrate sensitivity to modelling assumptions rather than to real land use impacts (Schumann, 1998).

In this study, the impact of drainage and afforestation on the hydrological regime is investigated on two catchments, the River Irthing at Greenholme $\left(334.6 \mathrm{~km}^{2}\right)$ and the Coalburn, a $1.5 \mathrm{~km}^{2}$ catchment nested within the larger catchment. The method uses indices of flow variability previously developed by Archer (2000), Archer and Newson (2002) and Newson et al. (2002) which specifically assesses the degree of variability.

Robinson (1993) noted a prevailing view among local residents that the river regime of the Irthing had changed towards increased variability to give more rapid and higher spates than previously. A recent questionnaire as part of this study has confirmed that this view is still widely held. As well as addressing the broader problem of finding a method for identifying land use impacts, this study assesses the reliability of local opinions based on casual or intermittent observations of the river.

\section{The catchments}

The River Irthing is a right bank tributary of the River Eden which drains parts of the English Lake District and Pennine Hills in northern England, and discharges to the Solway Firth and the Irish Sea. The Irthing drains the eastern slopes of the Pennines with elevations ranging from the highest point at Cold Fell $(621 \mathrm{~m} \mathrm{OD})$ in the south-east of the catchment to approximately $25 \mathrm{~m}$ OD at the outflow gauging station at Greenholme (Fig. 1). The Coalburn is a headwater tributary of the Irthing on its northern upland margin and varies in altitude from 270 to $330 \mathrm{~m}$ OD.

The pattern of precipitation is closely dependent upon elevation, and annual total ranges from $1800 \mathrm{~mm}$ at high levels to less than $800 \mathrm{~mm}$ in the lower reaches. The areal average annual precipitation is $1052 \mathrm{~mm}$ for the Irthing at Greenholme and $1277 \mathrm{~mm}$ for the Coalburn.

The rolling upland of the catchment is covered predominantly by blanket peat 0.5 to $3 \mathrm{~m}$ thick, overlying glacial till. The upper catchment originally had a moorland vegetation of Molinia grassland, heather and peat bog species and was used for sheep grazing and for grouse shooting. This moorland vegetation persists on high land especially in the south-east, and grass and shrub moorland and grass heath occupy $34 \%$ of the Irthing catchment (based on Landsat imagery; Fuller et al., 1994). There are localised protected blanket peat wetland areas in the north of the catchment including Butterburn Flow.

Elsewhere the uplands have been afforested extensively (Fig. 1). Much of the Spadeadam Forest, managed by Forest Enterprise, lies within the northern part of the Irthing catchment where it comprises an area of $58.8 \mathrm{~km}^{2}(17.6 \%$ of the Irthing catchment). Approximately a further $5 \mathrm{~km}^{2}$ has been planted by private landowners giving a catchment total of $19 \%$ coverage. Until 2002 , only $3.05 \mathrm{~km}^{2}$ had been felled. The predominant species are Sitka spruce (Picea sitchensis) (77\%) and lodgepole pine (Pinus contorta) (18\%). Over $90 \%$ of the Coalburn catchment has been planted, mainly with Sitka spruce.

The Coalburn experimental catchment was established specifically to assess the influence of drainage and afforestation on river flows and water quality, and has been the subject of several research studies (Robinson, 1980, 1993, 1998 and Robinson et al., 1998). Afforestation of the Coalburn catchment occurred in the spring of 1973 and was preceded by drainage, carried out in 1972 . The land was ploughed with furrows $0.8 \mathrm{~m}$ deep and at $4.5 \mathrm{~m}$ spacing, giving a drainage density of about $200 \mathrm{~km} \mathrm{~km}^{-2}$. Turf ridges were created from the excavated material adjacent to the furrows to provide drier elevated sites for planting.

This pattern of land preparation and planting was common on deep peats within the Irthing catchment in the 1970s. However, the use of shallower drainage furrows and a regular system of cross drains was more widespread but there is no evidence to suggest a significantly different hydrological effect from the practice at Coalburn. Planting by Forestry Enterprise and its predecessor on the broader Irthing catchment occurred over a period of several decades commencing around 1950, building up to a peak in the late 


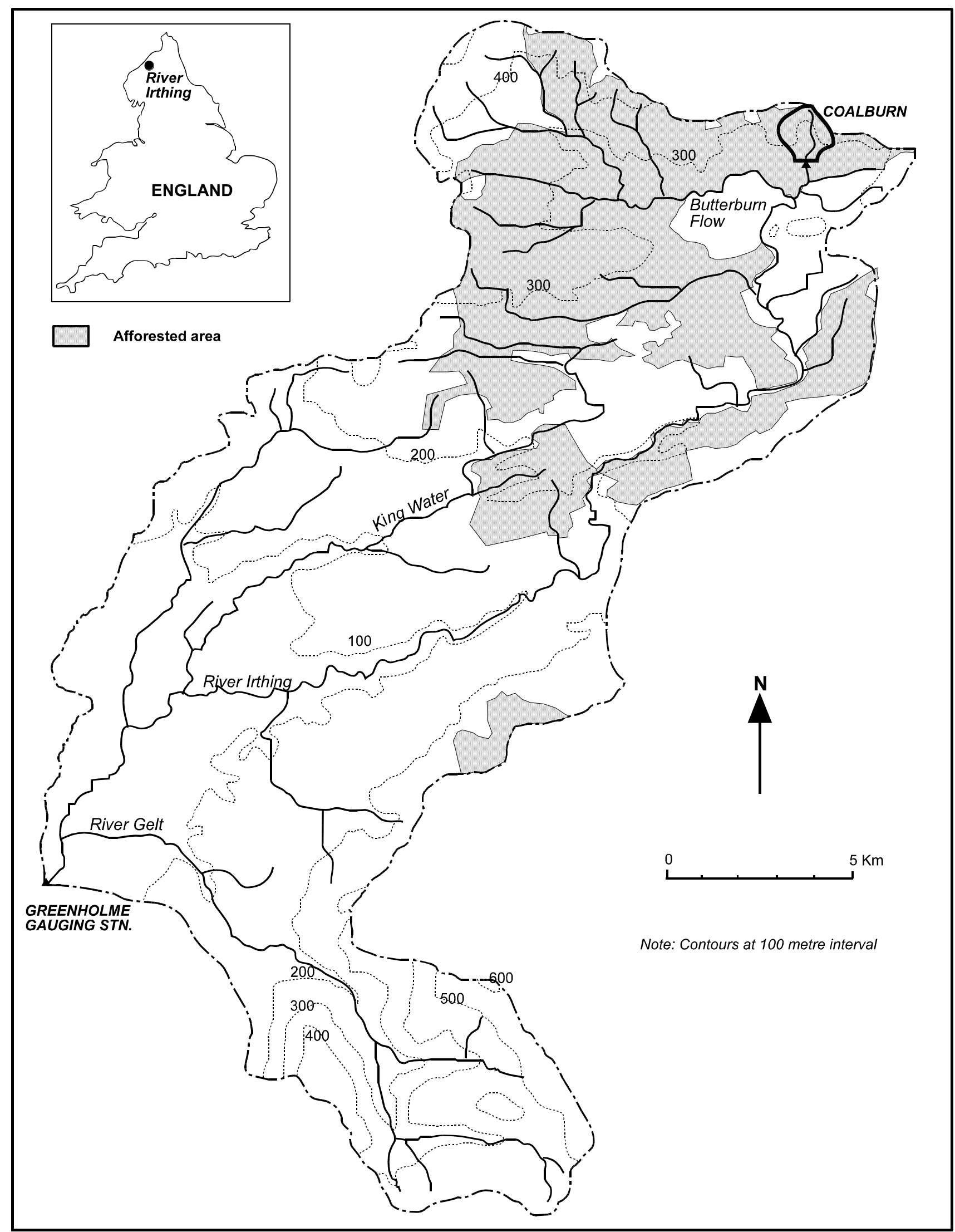

Fig. 1. The River Irthing catchment with (inset) its location in England. 
1960s (Fig. 2a), and with only limited planting in the 1980s and 1990s. The private forest is believed to have been mainly planted in the early 1970 s.

Archer and Newson (2002) demonstrate that at Coalburn the hydrological response is dominated by the drainage network for approximately 12 years after planting and the runoff is more flashy than under the initial moorland cover. After that period, the forest assumes a greater role in the runoff response which becomes much less flashy. Whilst forest growth rates vary with elevation, soils and exposure, it is believed that the Coalburn catchment, which is close to the mean elevation of the forested area of the Irthing and with similar mean precipitation, will approximate the mean development rate (with respect to hydrological impact) of the whole forest.

Figure $2 \mathrm{~b}$ shows the cumulative planted area, subdivided
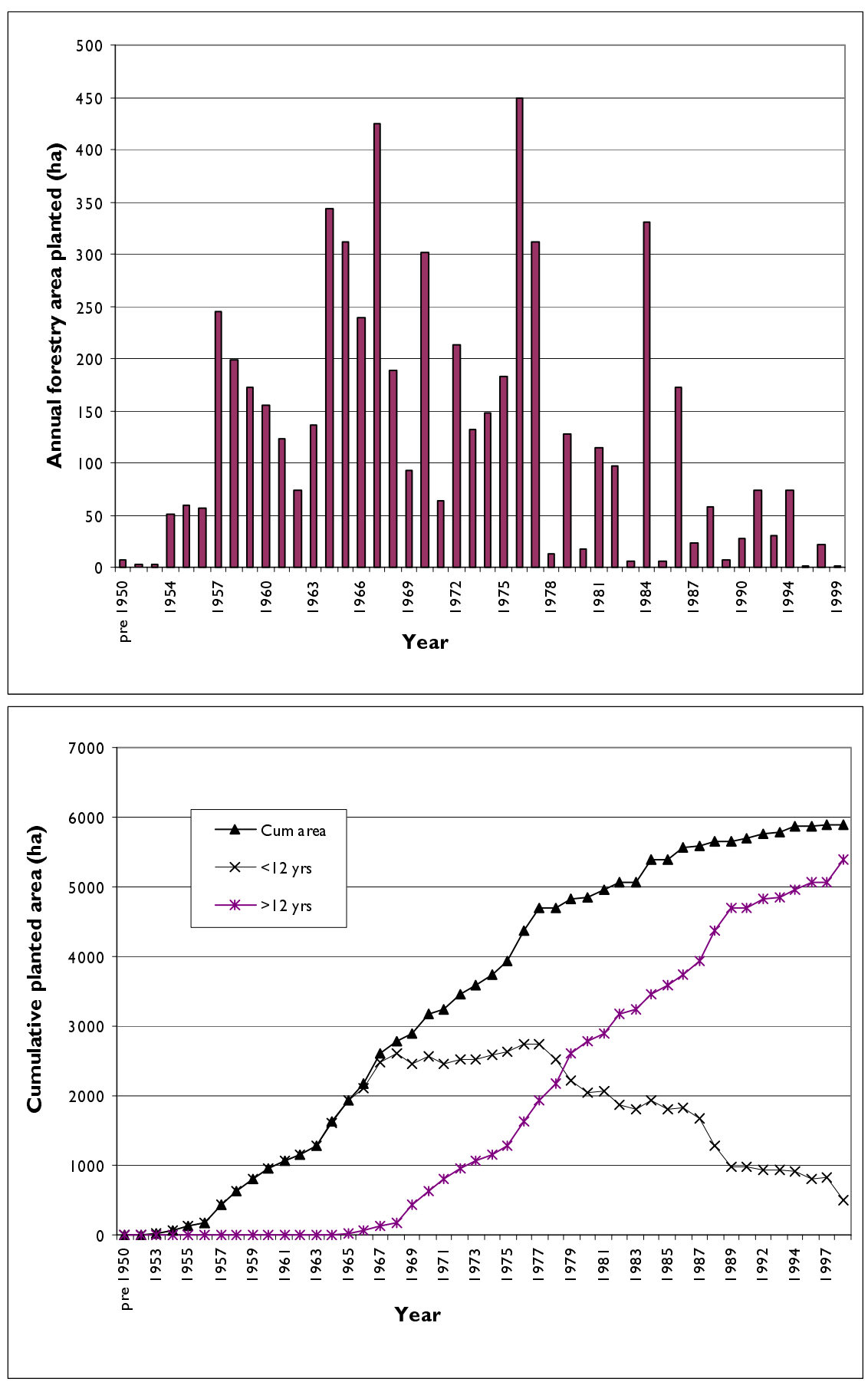

Fig. 2. Forestry area planted by Forestry Enterprise on the catchment of the River Irthing. A. Annual area planted, B. Cumulative planted area showing area above and below 12 years in age. 
between forest less than, and greater than, 12 years old. The figure shows that the area of drain-dominated forest probably reached a plateau from the late 1960s to early 1970s and was overtaken by forest greater than 12 years old in 1979 . At the end of the period (1999), forest greater than 12 years old represented $92 \%$ of the total.

Land use in the lower part of the catchment is predominantly pasture and meadow which together occupy $37 \%$ of the catchment - based on Landsat imagery. The proportion of arable land is small (7\%). The urban area is less than $1 \%$ of the catchment and largely unchanged.

\section{Data}

Streamflow data are the primary requirement for this analysis and records are available for the Irthing at Greenholme from 1968 to 1998 . The Greenholme gauging station was initially a gabion weir, altered in 1975 to an informal Flat-V weir and in both cases rated by current meter gauging by wading and a permanent cableway. The earlier period of record is of lower quality with frequent shifts in the stage discharge relationship. The record for 1975 is incomplete. A digital record at 15-minute interval based on float measurement with punched tape or solid state logger is available from 1976, whilst prior to that date a chart recorder was installed and the data are available on microfilm. Areal rainfall has been calculated from a network of daily gauges operating within and adjacent to the catchment

The flow record for the River Irthing does not cover the full period of land use change from moorland through drainage and forest development, but commenced in 1968 when $44 \%$ of the total forested area had already been planted. At this time, $94 \%$ of the forest was under 12 years in age and the expected impact of drainage was close to the maximum for the whole period.

The gauging station at Coalburn consisted of a compound Crump profile weir from its inception in 1967 to 1991 when it was replaced by a broad-crested weir structure with a central V-notch which contains flow for $98 \%$ of the time. In both cases the weirs are modular throughout the flow range and rated theoretically. The record for 1991 is not available and there are missing data periods of several months in 1972 and 1973, unfortunately during the period between ditching and planting. The record is digital and at 15-minute intervals throughout. An automatic weather station with recording raingauge within the catchment has operated since 1971, supplemented by four ground level gauges with records from 1967.

\section{Method}

The method of analysis of hydrological variability or disturbance has been described by Archer and Newson (2002). Essentially, it is based on the frequency and duration of pulses above threshold flows, selected as multiples of the median flow (Fig. 3). A pulse is an occurrence of a rise above a given flow, and pulse duration (between arrows) is the time from rising above the threshold to falling below the same threshold. The 15-minute digital flow record was analysed in yearly blocks. For each year the total number of pulses was counted and the total duration above the threshold for the year and the mean duration per pulse was computed. Incomplete pulses at the beginning and end of the year were excluded. The full spectrum of disturbance was assessed by repeating for 18 selected multiples of median flow (M) for the full period, as $0.5 \mathrm{M}, \mathrm{M}, 2 \mathrm{M}, 3 \mathrm{M}$, $4 \mathrm{M}, 5 \mathrm{M}, 6 \mathrm{M}, 7 \mathrm{M}, 8 \mathrm{M}, 10 \mathrm{M}, 15 \mathrm{M}, 20 \mathrm{M}, 30 \mathrm{M}, 40 \mathrm{M}, 50 \mathrm{M}$, $60 \mathrm{M}, 80 \mathrm{M}$ and $100 \mathrm{M}$. For the incomplete years in 1972 and 1973 at Coalburn, mean duration only was computed for the available period. Manual analysis of the pre-digital chart record at Greenholme was found to be tedious, and pulse number and duration were derived for four multiples of the median only $-5 \mathrm{M}, 10 \mathrm{M}, 15 \mathrm{M}$ and $20 \mathrm{M}$.

\section{Results}

The time series of the annual number of pulses, the total annual duration above each threshold and mean pulse duration were derived for both Irthing and Coalburn. As examples, pulse numbers for $15 \mathrm{M}$ and $20 \mathrm{M}$ are shown in Fig. $4 \mathrm{a}$ for Coalburn and $4 \mathrm{~b}$ for the Irthing. From this limited sample the following observations are made:

- There is considerable year to year variation in pulse numbers but broad correspondence between years of high and low pulses on the two catchments.

- Pulse numbers are significantly greater at Coalburn catchment than on the larger Irthing catchment

- At Coalburn pulse numbers are greatest in the late 1970s and early 1980 s in the period following drainage and whilst trees provided limited cover. The years immediately following planting (1974 to 1976) were exceptionally dry and the effect of drainage did not become evident in those years.

- At Coalburn there is a clearly decreasing trend in the number of pulses after 1980 and, by the end of the period, pulse numbers appear to fall below those occurring under moorland conditions from 1967 to 1971.

- For the Irthing the maximum in the late 1970s is not 
present but there is a weak suggestion of a declining trend in pulse numbers from the mid-1980s onward.

The above observation at Coalburn and examination of time series of pulse numbers for other thresholds and equivalent analysis for total and average duration above each threshold suggested that the data showed both a step change and trend related to land use change (Archer and Newson, 2002). Pulse number and duration above each threshold were therefore calculated for the entire period and for four time blocks:
(1) $1967-1971$
(2) $1974-1982$
(3) $1983-1990$
(4) $1992-1999$

\begin{abstract}
Pre drainage
Immediate post drainage and planting Intermediate period

Approaching/reaching canopy closure
\end{abstract}

Whilst there are clear differences in the phasing of drainage and planting between Coalburn and Irthing, it was considered preferable to retain the same analysis periods for both stations, rather than attempt to define new periods for the Irthing based on stage of forest growth. In this way the impact of annual climate on between-catchment comparison of period statistics has been minimised.

The relationship between pulse number and flow threshold is shown for the full period and for each of the sub-periods at Coalburn in Fig 5a and the Irthing in Fig. 5b. At Coalburn the land use influences are clearly demonstrated. Following drainage and planting pulse numbers rise well above the number under moorland cover, then progressively decline with approaching canopy closure. At the maximum pulse number at $3 \mathrm{M}$, there is a decline of more than 20 pulses such that in the latest period the number of pulses is less than for the Irthing, a catchment more than 200 times its area. For the larger Irthing catchment, the evidence for land use impact is not nearly so clear. At $3 \mathrm{M}$ there is no obvious change in the average number of pulses through the period; the highest number of pulses occurs during the period 1983 to 1990 whilst low pulse numbers occur both in the earliest period from 1968 to 1971 and in the most recent period from 1992 to 1999. It is noted that on the Irthing there are few pulses over 40M.

Similar analysis has been carried out for total annual pulse duration and the mean duration of pulses.

Part of the variation in each of the measures is due to the

A

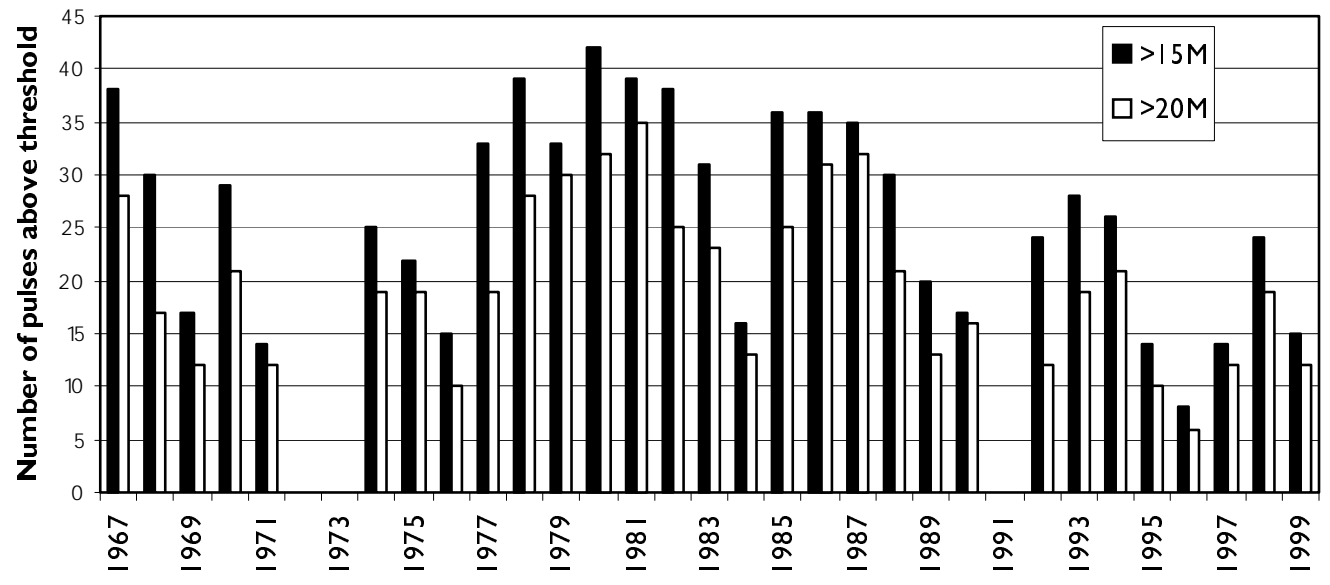

B

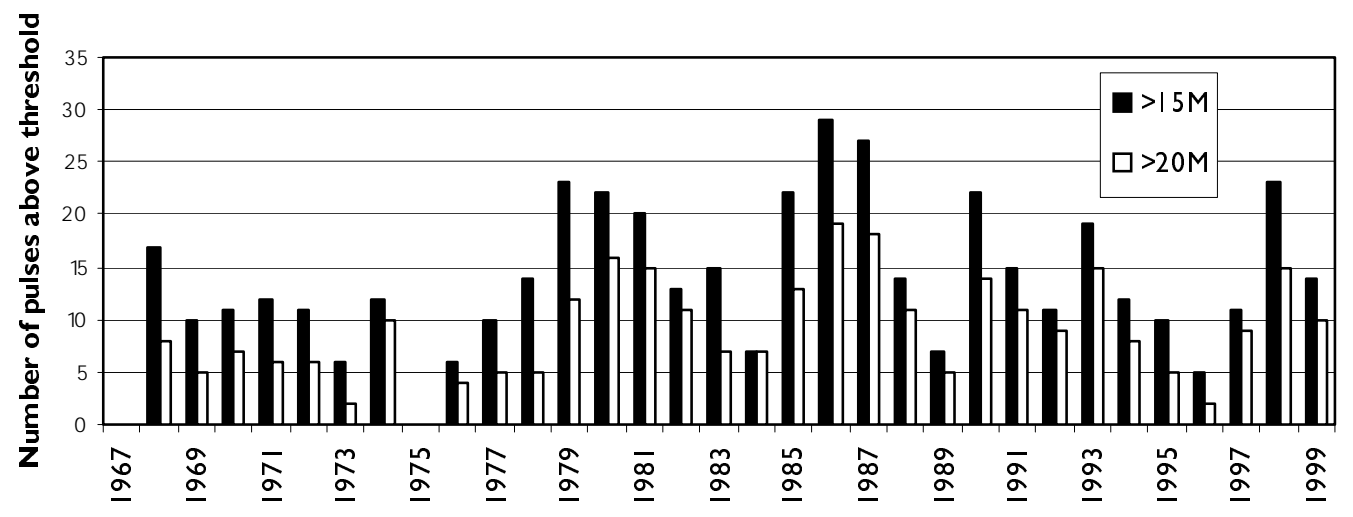

Fig. 4. Time series of the annual number of pulses above thresholds of 15 and 20 times the median flow for A. Coalburn, B. River Irthing at Greenholme 
weather and climate conditions of the particular year. To assess the impact of climate (and to isolate its effects from those of catchment and land use conditions), correlation and linear regression analyses were carried out between each set of annual pulse numbers, total and mean duration and the annual catchment rainfall for 1967 to 1997 . Table 1 shows the results of this regression analysis.

Significant correlations were found for both stations with each of the measures of flow variability over a wide range of discharge. However, there is a strong contrast between the two stations, with much higher correlation coefficients for the Irthing, extending down to lower multiples of median flow. It was shown by Archer and Newson (2000) that the lower correlation coefficients for the Coalburn were due to the additional effects of land use change whose influence was demonstrated by time trend in the residuals from regression with annual rainfall. The higher correlation coefficients for the Irthing imply that land use has a much more restricted influence on the larger catchment.

Correlation and regression were also carried out between

A

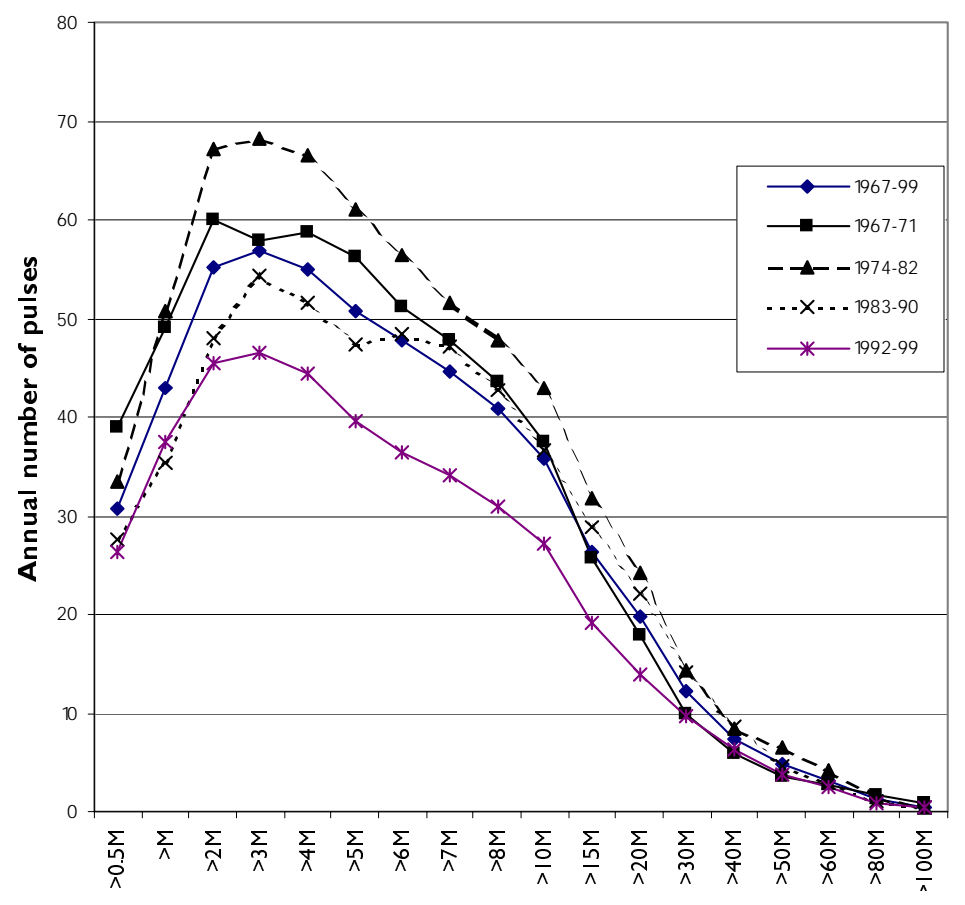

B

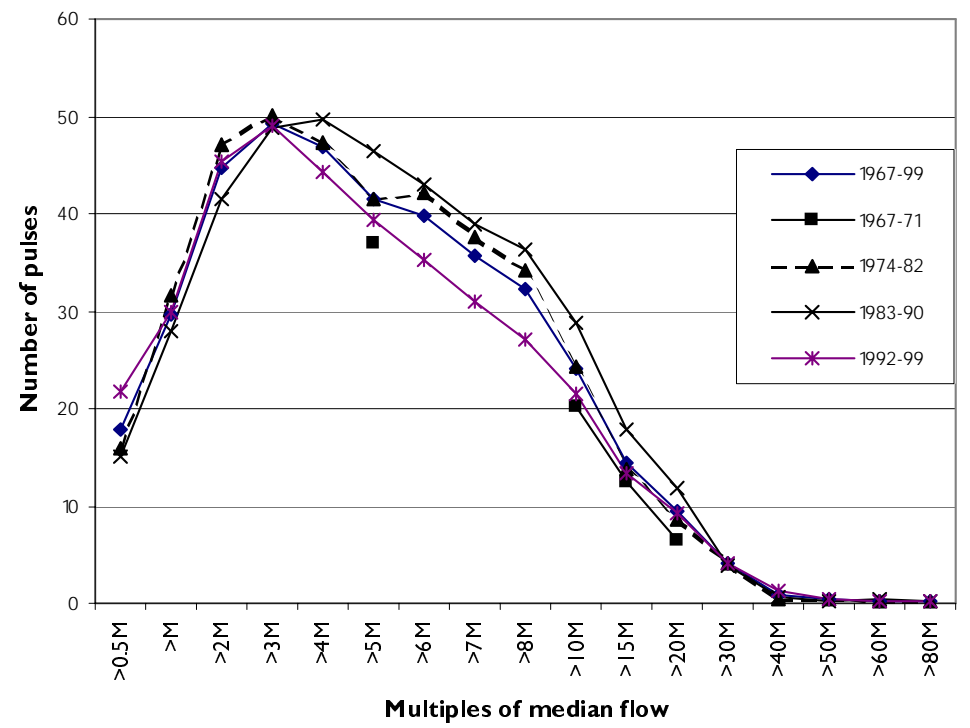

Fig. 5. Annual number of pulses over the full range of flow comparing pre-and post drainage and planting periods for A. Coalburn, B. Irthing at Greenholme. 
flow variability statistics and the annual number of daily rainfall totals exceeding a threshold but it was found that correlation coefficients between flow pulse numbers and daily rainfall exceedences were always inferior to annual rainfall irrespective of the daily rainfall threshold chosen.

The linear relationships with annual rainfall were therefore used as a basis for removing the effect of rainfall variability at both stations. For each year and flow threshold, the expected number and duration of pulses was calculated from catchment rainfall using the appropriate regression equation. The expected number was then subtracted from the observed value to give a residual with zero mean for the full period.

The time series of residuals of pulse numbers (which represents the departures from the regression line with annual rainfall) is shown as an example in Fig 6a and 6b for $15 \mathrm{M}$ and $20 \mathrm{M}$ for pulse numbers.

The residual annual number of pulses for the full range of flow thresholds is shown in Fig. 7a for Coalburn and 7b for the Irthing but divided between the previously chosen sub-periods of land use change. Similar comparisons are made in Fig. 8a and $8 b$ for the total duration and Fig. 9a and $9 \mathrm{~b}$ for mean pulse duration.

The sequence of Figs. 6 to 9 provide a comprehensive basis for comparing the flow variability of the two catchments and how it has changed over time. Reference is made mainly to flows in the range where significant correlations are found between annual rainfall and the flow variability indices (Table 1). At flows below $2 \mathrm{M}$, actual pulse numbers decrease due to the coalescence of pulses, giving a sharply increased pulse duration, but in wet years the flow may less frequently fall below $\mathrm{M}$, thus resulting in fewer pulses.
Figure $6 \mathrm{a}$ for Coalburn shows clear time-trends in residual pulse numbers for selected multiples of the median $-15 \mathrm{M}$ and 20M. Positive residual pulse numbers occur in all post drainage years to 1983 with the exception of 1974 and the severe drought year 1976. Residuals are mixed in the 1980s but are entirely negative from 1990 onward. The trend towards lower pulse frequency reflects both the progressive cover afforded by the forest stand and its influence on interception, evaporation and soil moisture storage, and the declining effects of artificial drains as they become degraded, blocked and vegetated. The Irthing (Fig. 6b) in contrast has generally lower pulse variability than Coalburn but little evidence of time trend at the discharge thresholds shown.

Similar analysis (not illustrated) shows a sharp decline in residual average pulse duration at Coalburn following drainage. Thereafter, from the late 1970 s, there was a steady increase in average pulse duration to the end of the period of observation. The Irthing again shows little evidence of trend with only the suggestion of increased pulse duration in the 1990s.

Figure 7 shows the change in residual pulse numbers by period over the whole flow spectrum. At Coalburn the increase in pulse numbers is seen to be quite modest following drainage, in comparison to the massive reduction with forest growth. Already by 1983 to 1990 (10 to 17 years after planting) annual pulse numbers had fallen well below the number occurring with the moorland cover. Further substantial reduction occurred throughout the range of flow in the 1990 s with 15 to 20 lower pulse numbers over much of the flow range compared with the moorland and 20 to 25 less than post-drainage. $t$-tests of the difference in means between the different periods show greatest significance between Periods 2 and 4 (at 95\% level for the flow range

Table 1. Correlation coefficient (r) between annual rainfall and annual pulse number, total duration and mean duration of pulses above selected multiples of the median flow for A. Irthing at Greenholme and B. Coalburn.

(Note: Figures in bold are significant at $95 \%$ level)

\begin{tabular}{|c|c|c|c|c|c|c|c|c|c|c|c|c|c|c|c|c|c|}
\hline & $0.5 M$ & $M$ & $2 M$ & $3 M$ & $4 M$ & $5 M$ & $6 M$ & $7 M$ & $8 M$ & $10 M$ & $15 M$ & $20 M$ & $30 M$ & $40 M$ & $50 M$ & $60 M$ & $80 M$ \\
\hline \multicolumn{18}{|c|}{ A. IRTHING AT GREENHOLME } \\
\hline Ann. No. of pulses & 17.9 & 29.8 & 44.6 & 49.3 & 47.0 & 41.6 & 39.8 & 35.6 & 32.2 & 24.1 & 14.5 & 9.4 & 4.0 & 0.8 & 0.4 & 0.3 & 0.2 \\
\hline $\mathrm{R}$ - pulse numbers & -0.04 & -0.07 & 0.20 & 0.65 & 0.73 & 0.77 & 0.84 & 0.87 & 0.90 & 0.89 & 0.78 & 0.80 & 0.62 & 0.29 & 0.34 & 0.31 & 0.27 \\
\hline $\mathrm{R}$ - Total duration & 0.30 & 0.57 & 0.87 & 0.93 & 0.93 & 0.93 & 0.93 & 0.92 & 0.92 & 0.90 & 0.87 & 0.84 & 0.32 & -0.06 & 0.04 & 0.27 & -0.73 \\
\hline $\mathrm{R}$ - Mean duration & 0.37 & 0.58 & 0.71 & 0.68 & 0.69 & 0.62 & 0.57 & 0.52 & 0.48 & 0.54 & 0.45 & 0.49 & -0.02 & -0.26 & 0.02 & -0.47 & -0.75 \\
\hline \multicolumn{18}{|l|}{ B. Coalburn } \\
\hline Ann. No. of pulses & 30.7 & 43.0 & 55.2 & 56.9 & 55.0 & 50.8 & 47.7 & 44.7 & 40.9 & 35.7 & 26.3 & 19.7 & 12.2 & 7.4 & 4.8 & 3.1 & 1.2 \\
\hline $\mathrm{R}$ - pulse numbers & -0.27 & -0.19 & -0.04 & 0.15 & 0.19 & 0.30 & 0.34 & 0.42 & 0.52 & 0.49 & 0.62 & 0.64 & 0.63 & 0.58 & 0.46 & 0.29 & 0.38 \\
\hline $\mathrm{R}-$ Total duration & -0.11 & 0.33 & 0.42 & 0.48 & 0.50 & 0.56 & 0.59 & 0.64 & 0.65 & 0.69 & 0.74 & 0.70 & 0.67 & 0.57 & 0.46 & 0.38 & 0.30 \\
\hline $\mathrm{R}$ - Mean duration & 0.17 & 0.55 & 0.51 & 0.49 & 0.48 & 0.40 & 0.52 & 0.50 & 0.40 & 0.44 & 0.26 & 0.15 & 0.06 & 0.14 & 0.08 & 0.13 & -0.15 \\
\hline
\end{tabular}


(a)

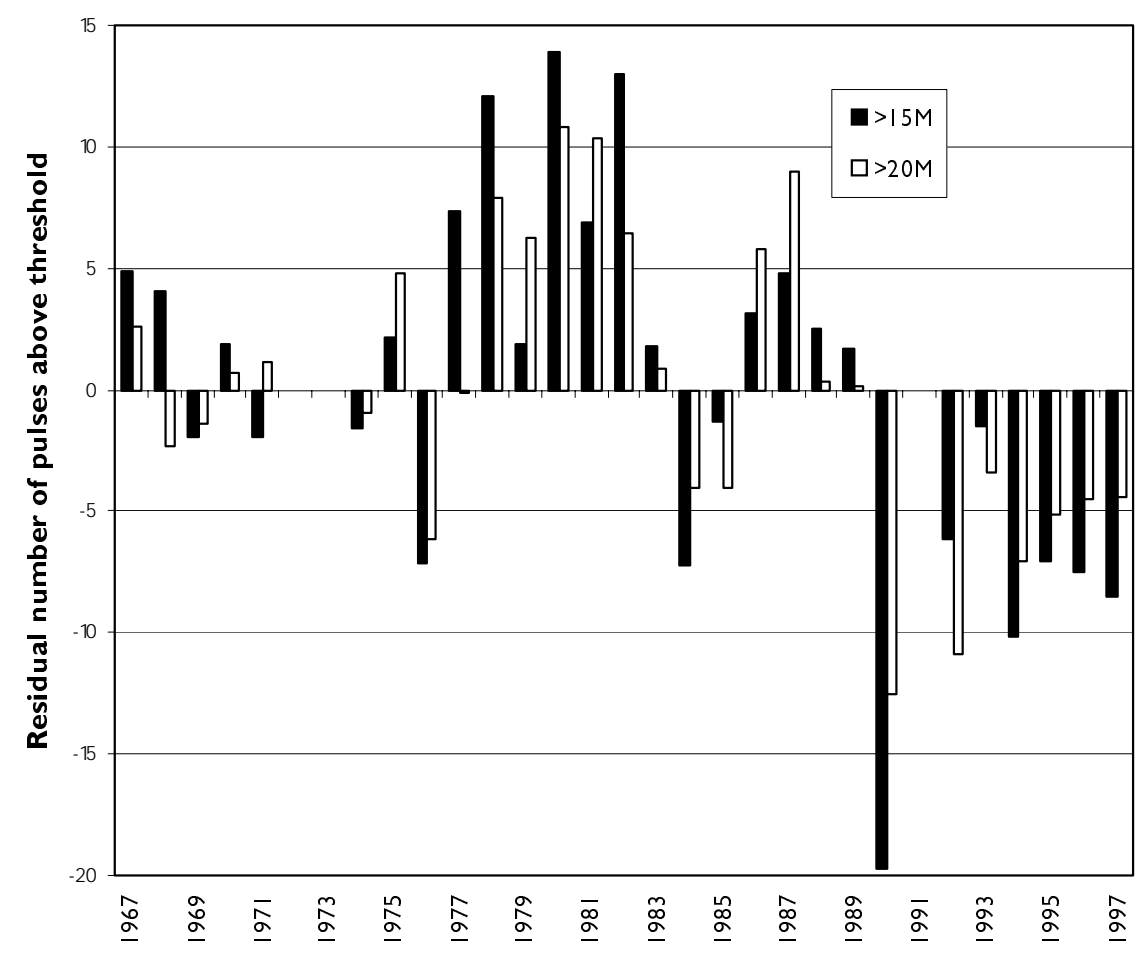

(b)

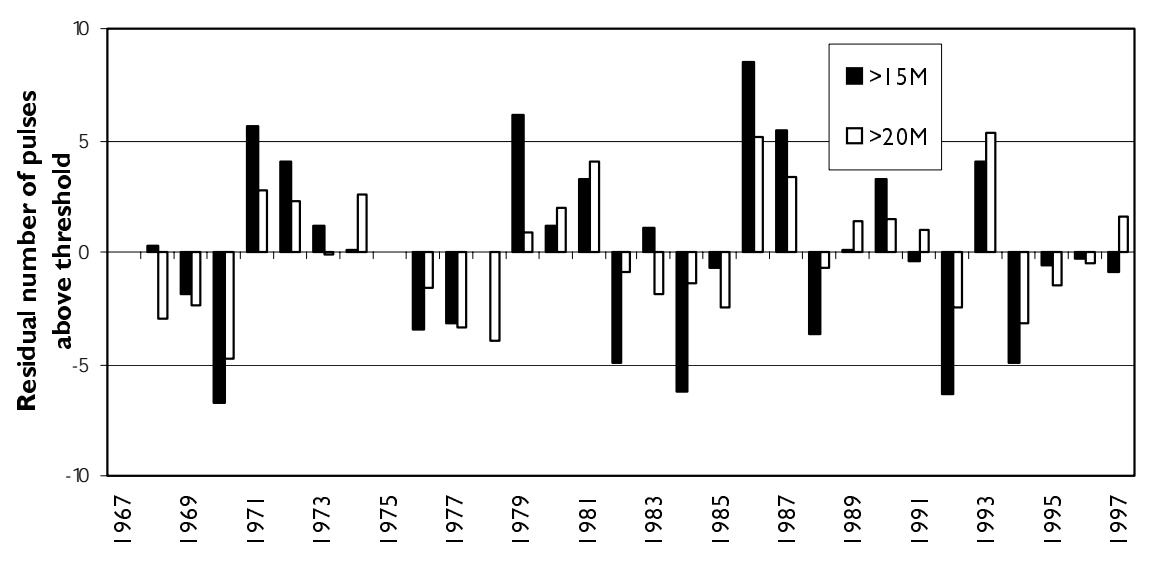

Fig. 6. Time series of residual annual pulse numbers above 15 and 20 times the median flow at Coalburn (top) and Irthing at Greenholme (below).

from $0.5 \mathrm{M}$ to $50 \mathrm{M})$, but significance over more restricted flow ranges between consecutive periods In spite of the consistent difference in residual pulse numbers between Periods 1 and 2 in Fig. 7 (pre- and post-drainage) the differences are not statistically significant.

On the Irthing, the only clear shift is during the 1990s towards lower pulse numbers than in the 1970s and 1980s but the maximum difference is only six pulses. Differences in period means are significant at $90 \%$ level for data in the flow range from $4 \mathrm{M}$ to $10 \mathrm{M}$ between Periods 2 and 4 and Periods 3 and 4 . The limited data from 1968 to 1971 suggest low pulse numbers during this period but this may reflect data quality rather than a real change.

Coalburn again shows distinctive patterns of changes in residual total duration of flow above at threshold (Fig. 8) with a sharp increase from moorland to the greatest duration in the immediate post drainage period over most of the flow range. Total duration then subsides to its lowest level in Period 4 with a difference of 350 hours at $3 \mathrm{M}$ between Period 2 and Period 4. Significance levels of change in total duration are lower than for pulse numbers and, for example, are only at $90 \%$ level over the flow range from $\mathrm{M}$ to $8 \mathrm{M}$ between 
(a)

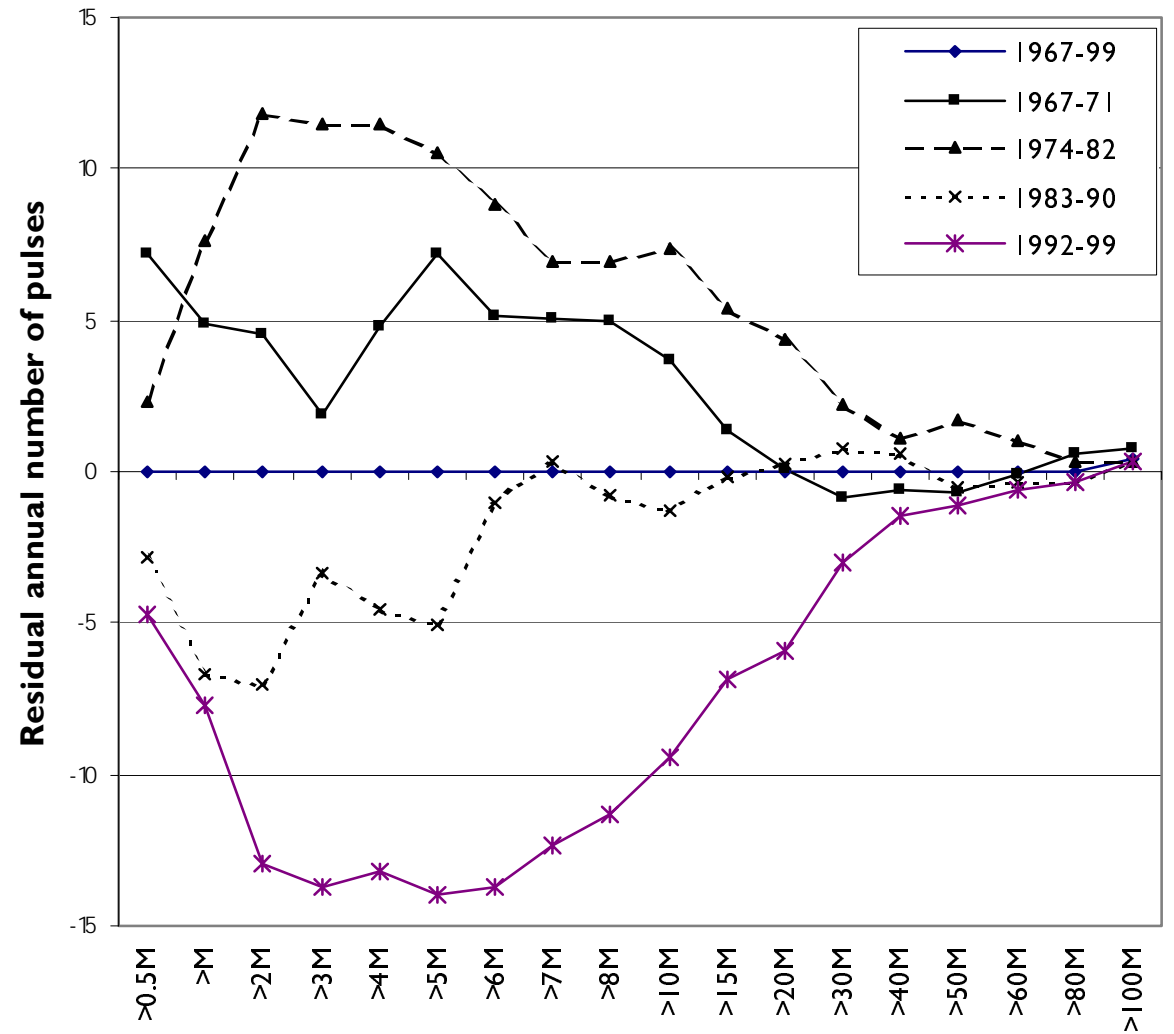

(b)

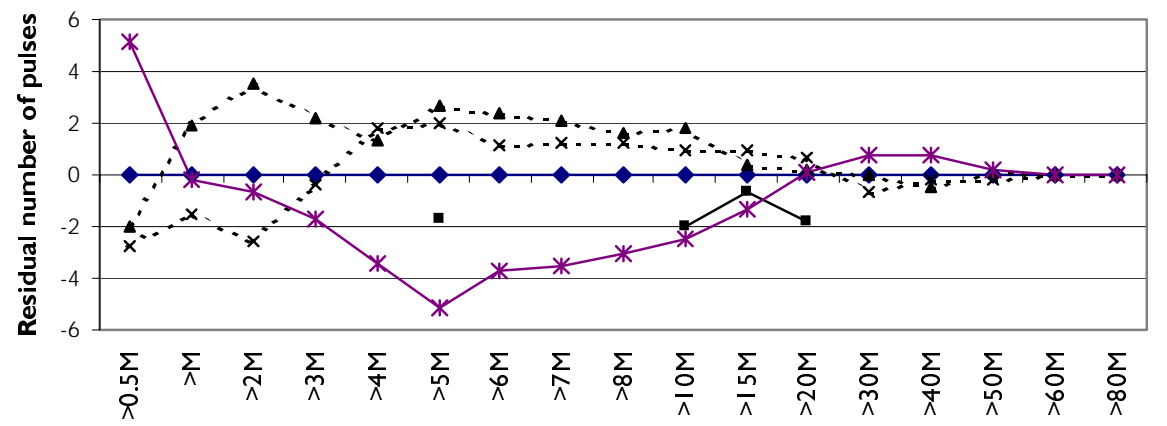

Multiples of median flow

Fig. 7. Comparison of residual annual pulse numbers over the full flow range for different periods in relation to drainage and planting for Coalburn (a) and Irthing at Greenholme (b).

Periods 2 and 4. The Irthing shows a similar pattern but with a smaller scale of change. There is an apparent increase from 1968-71 to the 1970s but again little difference over the next 20 years. The following period in the 1990s shows a decline but the difference for example at $3 \mathrm{M}$ between post drainage and the latest period is only 150 hours and is significant only at $90 \%$ in the flow range from $2 \mathrm{M}$ to $5 \mathrm{M}$.

With respect to residual average pulse duration (Fig. 9) Coalburn shows little change from moorland to postdrainage for moderate flows up to $10 \mathrm{M}$ but declining durations at higher flows. With progressive forest growth, pulse duration lengthens so that, for example, at $5 \mathrm{M}$ where the average pulse duration for the whole period is 18 hours, mean pulse duration is six hours longer in Period 4 than in Period 1 and the difference between these periods is significant at $95 \%$ level between $2 \mathrm{M}$ and $10 \mathrm{M}$ flows. However at flows above $40 \mathrm{M}$, the moorland pulse duration remains highest. The scale of changes in mean pulse duration is again much smaller on the Irthing than at Coalburn. There is little difference in mean pulse duration through the early record but then a significant increase of two hours in the flow range from $3 \mathrm{M}$ to $30 \mathrm{M}$ from the early periods to Period 4. 
(a)

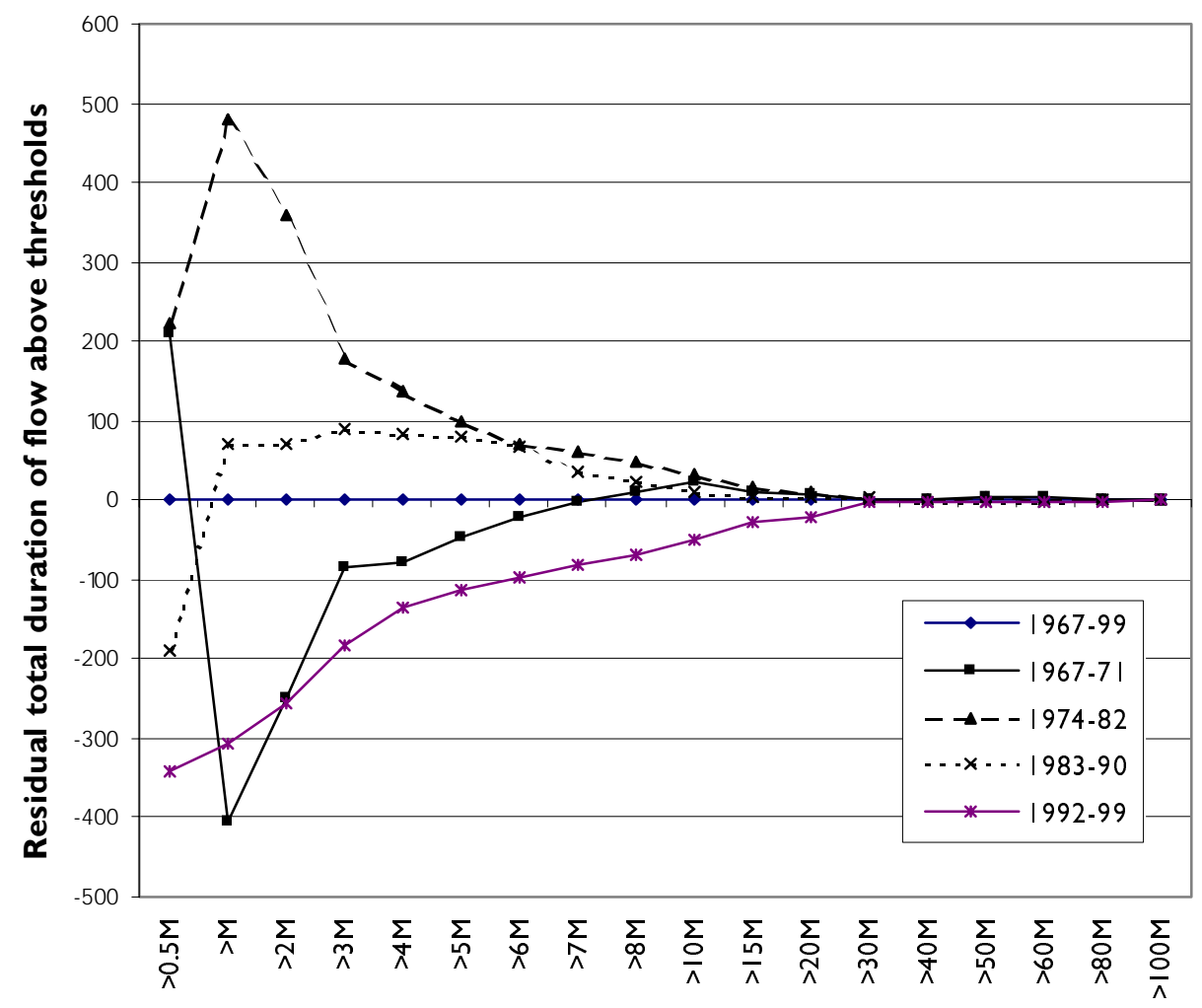

(b)

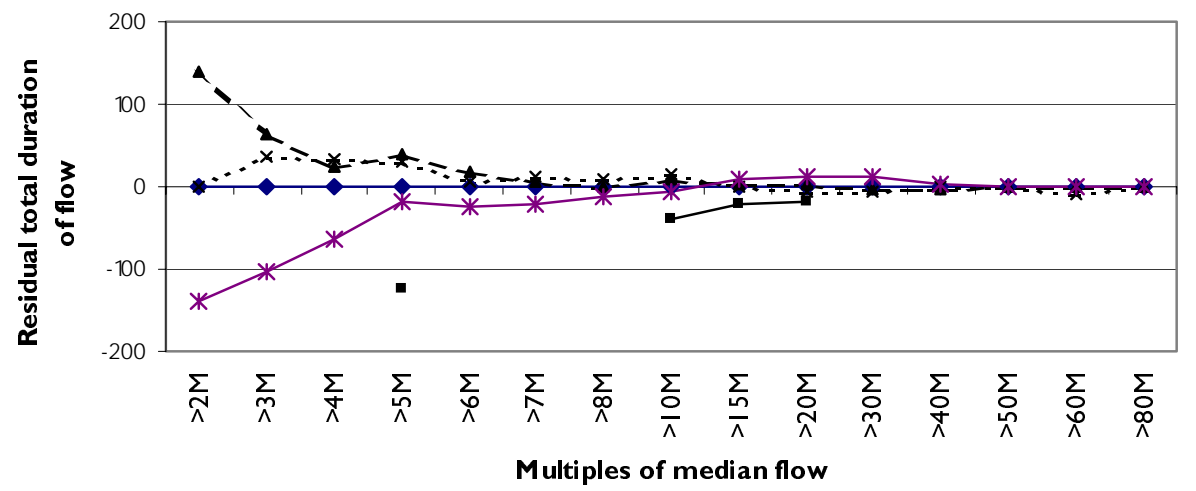

Fig. 8. Comparison of residual total duration of flow above thresholds for Coalburn (a) and Irthing at Greenholme (b).

\section{Discussion}

The assertion that the flow regime has changed on large catchments influenced by land use change in their headwaters as well as small catchments has frequently been made but rarely verified. Assertions are typically centred on the increased frequency and magnitude of floods or the perception that rivers now rise and fall more quickly and become more flashy than in the past. Robinson (1990) lists such assertions, including claims for the Tweed (Learmonth, 1950), Severn (Howe et al., 1967) and the Yorkshire Ouse (Caulfield, 1982). However, statistical evidence for change is hard to find in peak flood studies, given the sampling variability of extremes and the confounding influence of natural weather and climatic variability. The use of indices of flow variability provides a means of examining directly the assertion of changes in flashiness, but over a range of flows which occur more frequently and where there is therefore the opportunity to demonstrate and verify whether change has occurred or not.

This study provides evidence of the limited extent to which significant changes in flow variability in a headwater catchment translate to the larger downstream catchment. Whilst Fig. 5 illustrates the much smaller time variation in actual pulse numbers on the Irthing than on the Coalburn, Table 1 shows that much more of that small variation is 
(a)

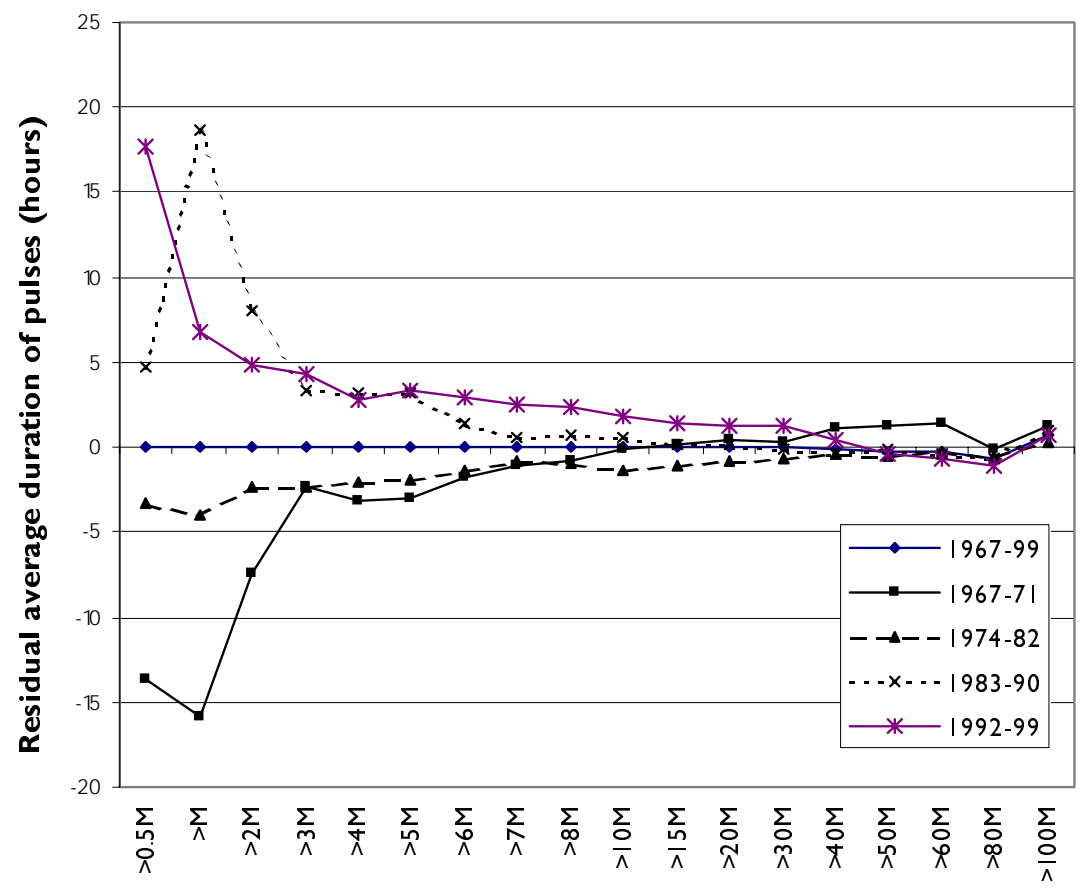

(b)

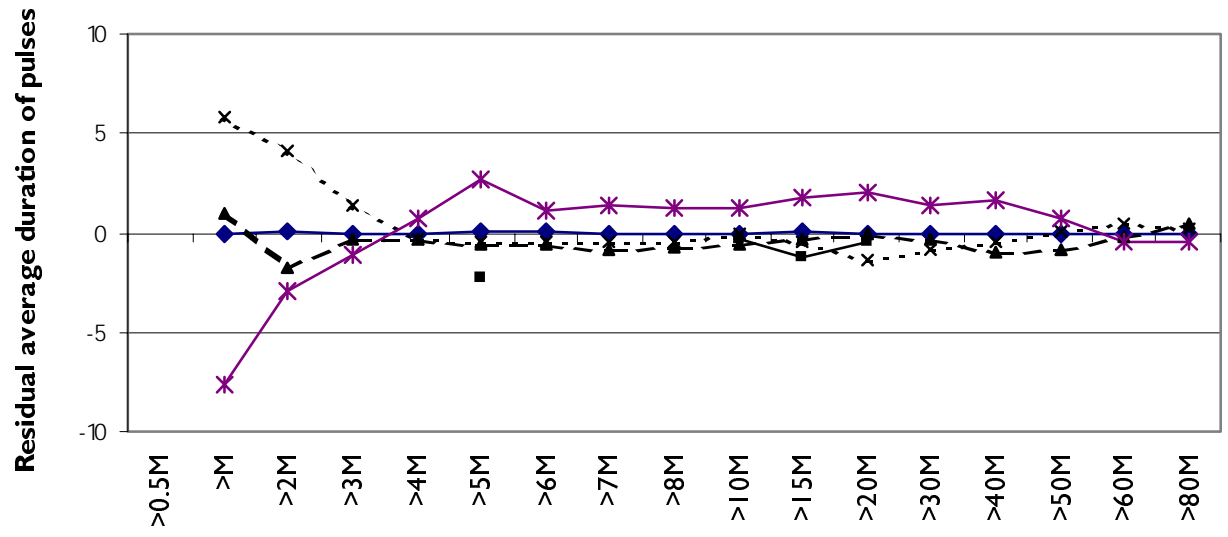

Multiples of median flow

Fig. 9. Comparison of residual average duration of flow above thresholds for Coalburn (a) and Irthing at Greenholme (b).

correlated with annual rainfall. Hence, when the residuals from regression are extracted, Figs. 6 to 9 show that the residual number of pulses (and pulse durations) are much smaller on the Irthing than for the upland tributary.

The only clear expression of land use influence on the downstream flow regime is in the most recent period of record since 1991 . By that date more than $85 \%$ of the forest had reached a stage at which (the evidence of Coalburn suggests that) canopy effects exceeded the counteracting effects of initial drainage. During this recent period on the Irthing there is a clear but comparatively small reduction in pulse numbers and an increase in mean pulse duration. The fact that these changes coincide with the concurrent pattern of change at Coalburn gives confidence in their origin as land-use driven. It is unfortunate that there is no hydrological record for the Irthing prior to afforestation. Nevertheless it is surprising that significantly higher pulse numbers in the post drainage period at Coalburn are not reflected in the earliest period of Irthing record from 1968 to 1971 when the comparative influence of drainage could be expected to be greatest.

There are several potential reasons for limited downstream land use influences, some already noted in the introduction, but uncertainty remains concerning physical processes.

(1) Whilst the hydrological impact of the forested area on the Irthing catchment should be greater than the planted area (the forest is located in the zone of highest rainfall 
and specific runoff), the catchment area affected by land use change is still much smaller on the Irthing (19\%) than at Coalburn $(>90 \%)$. More than $75 \%$ of the Irthing runoff response is unaffected by the impact of afforestation.

(2) It might be argued that the spread in time of forest planting from 1950 onward (Fig. 2) has resulted in conflicting hydrological signals from different parts of the forested area of the Irthing. Or indeed, it is conceivable that forest effects have been counterbalanced by changes in land use management practices (such as field drainage or stocking densities) in improved pasture and arable land in the lower reaches. However, the fact that most of the variation in flow variability indices for the Irthing is accounted for by climate (Table 1) leaves little scope for effects of land use influence of any kind - even assuming that all the variation resulting from climate is accounted for by annual rainfall.

(3) The hydrological regime of the downstream catchment is affected to a much greater extent by channel processes and lag which are largely unchanged by afforestation.

The observed change in the hydrological regime of the Irthing (and Coalburn) during the recent decade has been in the opposite direction to that postulated by river users. The scale of the change is such that it is most improbable that it could be detected by casual or intermittent observation by river users. The disparity between the results of this analysis which specifically addresses the problem of flow variability and the assertions of river users, casts some doubt on the validity of such assertions on other rivers in northern England. Clearly, further analysis on other rivers is necessary to confirm these findings.

\section{Conclusions}

Indices of flow variability provide a comprehensive means of assessing land use changes in time on a single catchment and for comparing responses between different catchments. In assessing the frequency and duration of pulses, they provide a direct measure of those properties of the hydrological regime that have been said to alter following land use change.

It is concluded that major and progressive changes have occurred in the headwater catchment at Coalburn. Annual pulse numbers have reduced by nearly $40 \%$ below those experienced under the moorland cover and are now little different from the number for the Irthing at Greenholme - a catchment 200 times its area. Pulse duration has increased by more than $20 \%$ over most of the flow range.

In contrast, on the lower River Irthing there has been little evidence of change from the beginning of the record in 1968 until the late 1980s. Thereafter pulse numbers have reduced and pulse duration has increased - a change in the same direction as at Coalburn but at a much smaller scale. Potential reasons for the reduced response on the larger catchment are:

- the smaller proportion of the catchment afforested,

- the patchwork nature of the forest development and the spread in time over which afforestation has occurred giving possible counteracting influences of preafforestation drainage and the expansion of the forest canopy,

- the change in the balance of hydrological processes from land based interception, infiltration and soil storage to channel processes.

The balance of these influences requires full investigation through process studies on catchments with a range of area. The CHASM initiative (Catchment Research and Sustainable Management) (O'Connell, 2003), which includes the Irthing amongst catchments being studied, offers an opportunity for such elucidation.

\section{References}

Archer, D.R., 2000. Indices of flow variability and their use in identifying the impact of land use changes. Proc. Seventh National Hydrology Symposium, British Hydrological Society, Sept 2000. 2.67-2.74.

Archer, D.R. and Newson, M., 2002. The use of indices of flow variability in assessing the hydrological and instream habitat impacts of upland afforestation and drainage, J. Hydrol., 268, 244-258.

Caulfield, C., 1982. Too much drainage spells trouble on t'farm, New Scientist, 21 Jan. 1982., 125.

Dooge, J.C.I., 1989. Scale Problems in Hydrology. Kisiel Memorial Lecture, February 1986, University of Arizona, Tucson, Arizona, USA. 63pp.

Fuller, R.M., Groom, G.B. and Jones, A.R., 1994. The Land Cover Map of Great Britain: an automated classification of Landsat Thematic Mapper data. Photogram. Eng. Remote Sens., 60, 553562.

Howe, G.M., Slaymaker, H.O. and Harding, D.M., 1967. Some aspects of the flood hydrology of the upper catchments of the Severn and Wye. Trans. Inst. Brit. Geogr., 41, 33-58.

Learmonth, A.T.A., 1950. The floods of $12^{\text {th }}$ August 1948 in southeast Scotland. Scottish Geograph. Mag., 66, 147-153.

National Research Council, 1991. Opportunities in Hydrologic Sciences. Academy Press, Washington DC, 348 pp.

Newson, M., 1994. Hydrology and the River Environment, Oxford University Press. 
Newson, M., Archer, D.R. and Newson, C., 2002. Expanding the definition of 'natural' instream physical habitat: flow variability and biotope diversity in a representative selection of UK river 'types', Proc. Fourth Int. Ecohydraulics Symp., Cape Town, South Africa, March 2002. (Web and CDRom published).

O'Connell, P.E., 2003. Catchment scale hydrological issues relating to land use management and river flows. ICE Conf. Land Use and Flood Management, January 2003.

Robinson, M., 1980. The effect of pre-afforestation drainage on the streamflow and water quality of a small upland catchment. Institute of Hydrology Report 73, Wallingford, UK.

Robinson, M., 1990. Impact of improved land drainage on river flows. Institute of Hydrology Report 113, Wallingford, UK.
Robinson, M., 1993. Impacts of plantation forestry on streamflow regimes - a case study. Proc. Fourth National Hydrology Symposium, British Hydrological Society. 2.41-2.45.

Robinson, M., 1998. 30 Years of forest hydrology changes at Coalburn; water balance and extreme flows. Hydrol. Earth Syst. Sci, 2, 233-238.

Robinson, M., Moore, R.E., Nisbet, T.R. and Blackie, J.R., 1998. From moorland to forest: the Coalburn catchment experiment. Institute of Hydrology Report 133, Wallingford, UK.

Schumann, A., 1998. Land use change. In: Encyclopedia of Hydrology and Water Resources, R.W. Herschy and R.W. Fairbridge (Eds.), Kluwer Academic Publishers, Dordrecht, The Netherlands. 466-467. 